\title{
Entre el arte y la técnica: la discrecionalidad policial en la investigación criminal. EI caso de la Policía de Seguridad Aeroportuaria en Argentina*
}

\section{Between art and technique: police discretion in criminal investigation. The case of the Airport Security Police in Argentina}

\author{
Mariana Gutiérrez \\ Doctoranda en Ciencia Política, Universidad Nacional de San Martín \\ Instituto Superior de Seguridad Aeroportuaria, Policía de Seguridad Aeroportuaria \\ mariana.gutie@gmail.com \\ Gabriel Costantino \\ Doctor en Ciencia Política, Universidad Nacional de San Martín \\ Instituto Superior de Seguridad Aeroportuaria, Policía de Seguridad Aeroportuaria \\ gcostant76@gmail.com
}

\section{Resumen}

El artículo examina el rol de la discrecionalidad policial en la investigación criminal en una de las policías federales de Argentina. La metodología combina técnicas cuantitativas y cualitativas de recolección y examen de la información para resolver diferentes niveles de análisis. Los resultados del trabajo muestran que los operadores judiciales y la agenda pública tienen un peso importante en cuánto, qué y cómo se investiga el delito en esta fuerza en la jurisdicción federal. Se comprueba también un espacio de discrecionalidad policial en la investigación criminal la cual es percibida como un saber-hacer necesario para la investigación de los delitos por actores judiciales y policiales; dicho saber-hacer se comprende como a mitad de camino entre el arte y la técnica. Consideramos que los resultados de la investigación contribuyen al debate informado sobre el diseño y la implementación de mejoras en el sistema de investigación del delito a nivel federal en Argentina.

Palabras clave: Discrecionalidad policial, Políticas criminales, Políticas de seguridad, Investigación criminal, Investigación policial.

\footnotetext{
Abstract

* El artículo presenta hallazgos parciales del estudio "La investigación criminal compleja en las fuerzas policiales y de seguridad federales. El caso de la PSA", que contó con el apoyo de la entonces Subsecretaría de Planeamiento y Formación del Ministerio de Seguridad de la Nación, Argentina. Agradecemos, en primer lugar, el respaldo de las autoridades del Instituto Superior de Seguridad Aeroportuaria y de la Policía de Seguridad Aeroportuaria para la realización de la investigación. En segundo lugar, el trabajo no hubiera sido posible sin el aporte y la colaboración de los diversos actores del sistema de investigación criminal federal que accedieron a prestar su testimonio y compartir sus experiencias. Agradecemos los comentarios y sugerencias de dos revisores anónimos. El contenido del artículo, así como cualquier error y/u omisión son de exclusiva responsabilidad de los autores.
} 
The article examines the role of police discretion in criminal investigation in one of the federal polices in Argentina. The methodology combines quantitative and qualitative techniques of data collection and analysis. Our preliminary findings show that judicial operators and the public agenda influence the quantity and types of crime investigated. On the other hand, we show that police discretion is perceived as a know-how necessary for efficient crime investigation by police and judicial actors; this know-how is also perceived as a mix of art and technique. We believe that the results of the investigation contribute to the informed debate on the design and implementation of improvements in the crime investigation system at the federal level in Argentina.

Keywords: police discretion, criminal policies, security policies, criminal investigation, police investigation.

\section{Introducción}

La reorganización de las instituciones policiales y penales para promover un sistema que garantice de forma equitativa y eficiente los derechos de la ciudadanía es un problema público recurrente en las democracias latinoamericanas. ${ }^{1}$ En la región, un sector importante de los especialistas y la opinión pública considera que la discrecionalidad de la policía ${ }^{2}$ afecta negativamente las investigaciones criminales. Por ejemplo, expertos en el funcionamiento de la rama penal del sistema judicial ${ }^{3}$ y de la organización y las prácticas policiales ${ }^{4}$ han argumentado que la conducción de la investigación criminal es delegada en manos de la policía, quien investiga por su cuenta, direccionando las pesquisas hacia fines particulares y muchas veces ilegales.

Otra parte de la literatura, sin embargo, problematiza la idea de la discrecionalidad policial desde un punto de vista distinto, asociándola a un saber-hacer en la labor policial y/o a criterios coincidentes con demandas provenientes de las instituciones judiciales, la sociedad civil e inclusive los medios de comunicación. ${ }^{5}$ En Argentina, a pesar de la cantidad de

\footnotetext{
${ }^{1}$ MÉNDEZ et al. (2002), passim; CENTRO DE ESTUDIOS DE JUSTICIA DE LAS AMÉRICAS (2007), passim; CENTRO DE ESTUDIOS DE JUSTICIA DE LAS AMÉRICAS (2013), passim; CENTRO DE ESTUDIOS LEGALES Y SOCIALES (CELS) (2004), passim; OFICINA DE LAS NACIONES UNIDAS CONTRA LA DROGA Y EL DELITO (UNODC) (2004), passim; OFICINA DE LAS NACIONES UNIDAS CONTRA LA DROGA Y EL DELITO (UNODC) (2010), passim.

${ }^{2}$ En su acepción más amplia, la discrecionalidad policial se refiere a la gran libertad de acción que tiene el policía en las diferentes manifestaciones de la actividad policial, véase apartado 2.

${ }^{3}$ BINDER (2002), pp. 67-72; CENTRO DE ESTUDIOS DE JUSTICIA DE LAS AMÉRICAS (CEJA), (2005), passim; DUCE (2005), pp. 65-82; ARSLANIÁN (2011), passim. CENTRO DE ESTUDIOS LEGALES Y SOCIALES (CELS) (2004), passim; OFICINA DE LAS NACIONES UNIDAS CONTRA LA DROGA Y EL DELITO (UNODC) (2004), passim; OFICINA DE LAS NACIONES UNIDAS CONTRA LA DROGA Y EL DELITO (UNODC) (2010), passim.

${ }^{4}$ SAIN (2002), passim; SAIN (2007), passim; SAIN (2015); CAMOU y MORENO (2005), pp. 141-172; DEWEY (2015), passim.

${ }^{5}$ BRODEUR (2011), passim; MONJARDET (2010), passim; BIANCIOTTO (2013), pp. 305-326.
} 


\section{Polít. Crim. Vol. 15, No 29 (Julio 2020), Art. 1, pp. 25-46 [http://politcrim.com/wp-content/uploads/2020/01/Vol15N29A1.pdf]}

estudios existentes sobre temas policiales emparentados, ${ }^{6}$ notamos que la literatura experta ha abordado en menor medida la relación entre discrecionalidad policial e investigación criminal. $^{7}$

El presente artículo procura aportar a este campo de estudio, a través del análisis de las prácticas de investigación criminal de delitos llevadas a cabo por la Policía de Seguridad Aeroportuaria (PSA) en Argentina. Preguntas orientadoras de este trabajo son: ¿En qué medida los policías son libres en la elección de qué investigar y cómo investigarlo? ¿Qué intereses, saberes y destrezas ponen en juego a la hora de participar en las investigaciones?

La PSA es una de las cuatro fuerzas policiales y de seguridad federales que integran el sistema de seguridad interior argentino, siendo la autoridad superior responsable de la seguridad aeroportuaria. Su misión consiste tanto en la seguridad aeroportuaria preventiva - orientada a prevenir, conjurar e investigar los delitos y las infracciones en el ámbito aeroportuario - como en la seguridad aeroportuaria compleja -que procura el control y la conjuración de los actos delictivos complejos cometidos por organizaciones criminales, relacionados con el narcotráfico, el terrorismo, el contrabando y otros delitos conexos ${ }^{8}$. Si bien se trata de un cuerpo policial de dimensiones reducidas en comparación con sus pares federales, ${ }^{9}$ esperamos que su estudio contribuya a comprender el funcionamiento de la investigación criminal en el nivel federal, a la vez que permita tomar distancia de ciertas generalizaciones repetidas sobre las policías argentinas, que promueven diagnósticos y propuestas de reforma mejorables.

La organización del trabajo es la siguiente. En la sección 1 presentamos una revisión crítica de los principales estudios sobre investigación criminal y esbozamos el enfoque a partir del cual encuadramos la investigación. En la sección 2 presentamos una revisión crítica de los principales estudios sobre investigación criminal y esbozamos el enfoque a partir del cual encuadramos la investigación. En la sección 3 explicamos el diseño metodológico, detallando las técnicas de recolección y análisis de información que utilizamos. La sección 4 presenta los principales resultados de nuestro estudio, referentes a la organización de la persecución criminal en el caso analizado (3.1), el espacio de la discrecionalidad policial en la investigación criminal (3.2), y al tipo de saber-hacer que implica dicha discrecionalidad policial (3.3). Finalmente, en la sección 5 discutimos los corolarios de la investigación, su contribución a la literatura académica y a la generación de un diagnóstico más preciso sobre la investigación criminal del delito en Argentina.

\footnotetext{
${ }^{6}$ Entre otros, podemos nombrar: la formación policial, la profesión policial, las reformas policiales, el vínculo policial con los mercados ilegales. Estados del arte actualizados sobre estos objetos de estudio pueden encontrarse en FREDERIC et al. (2013), passim; LORENZ (2018), pp. 347-369; ESCUDERO (2017), pp. 83113; GONZÁLEZ (2017), passim.

${ }^{7}$ Los trabajos que han estudiado la temática en Argentina han sido principalmente de corte jurídico (BINDER (2002), passim; ARSLANIÁN (2011), passim; confróntese, BIANCIOTTO (2013), passim; RENOLDI (2010), pp. 95-120). En las secciones 2 y 3 especificamos cómo nuestro trabajo se inscribe en esta tradición de estudio y los aportes que esperamos brinde a su desarrollo.

${ }^{8}$ Ley $\mathrm{N}^{\circ} 26.102$, art. 12, 2.

${ }^{9}$ En promedio, el presupuesto de la PSA es 8 veces menor que el de las otras fuerzas policiales y de seguridad federales (Gendarmería Nacional, Prefectura Naval y Policía Federal); y su planta de personal es cinco veces más pequeña (confróntese COSTANTINO y GUTIÉRREZ (2017), pp. 59-90, p.72).
} 


\section{Antecedentes}

Las ciencias sociales suelen abordar el trabajo policial en torno al estudio de su discrecionalidad. " 10 a gran libertad de acción de la cual dispone el policía operativo, el policía local en su barrio, la patrulla en su ronda, el equipo durante su servicio, diferentes manifestaciones del policía uniformado en la vía pública", ${ }^{11}$ han motivado esta concentración en el fenómeno, que se ha extendido luego a otras categorías de policías, como los investigadores criminales.

En América Latina, varios especialistas comparten esta perspectiva aplicada a la policía en general y a la investigación criminal en particular. Como adelantamos más arriba, una crítica difundida en la literatura regional sobre el sistema de persecución penal sostiene que la conducción de la investigación criminal suele ser delegada por los jueces en manos de la policía. En esta visión, esta investiga por su cuenta y es quien termina direccionando las pesquisas, mientras los magistrados sólo reactivamente reciben los resultados enviados por las agencias policiales. ${ }^{12}$ Estos estudios han solido enfatizar el aspecto negativo de la discrecionalidad policial, proponiendo la reorientación del sistema judicial desde un modelo inquisitorio hacia uno acusatorio, de modo que las investigaciones sean conducidas por fiscales -quienes son vistos como más capacitados, más selectivos y más garantistas-, con el objeto de lograr una mayor eficacia y equidad en la investigación criminal. ${ }^{13}$

De manera similar, otro grupo de estudios explica las falencias en la persecución de los delitos a partir de la existencia de un pacto político-policial-criminal, mediante el cual los políticos delegan en los policías la autonomía para regular sus actividades -lo cual incluye el involucramiento en negociados criminales- a cambio de mantener el conflicto y el delito en niveles aceptables. ${ }^{14}$ Según este argumento, el gobierno dejaría librado al criterio de las fuerzas policiales qué delitos investigar, de qué manera y en qué medida, lo cual redundaría a su vez en altos niveles de impunidad, corrupción y violencia institucional. Estos estudios concluyen en la necesidad de aumentar los controles civiles sobre la policía, tanto por parte del gobierno, como del ministerio público, la justicia y la sociedad civil. ${ }^{15}$

Ahora bien, existen otros trabajos expertos que examinan la idea de la discrecionalidad policial desde una perspectiva diferente, asociándola a un saber-hacer en la labor policial. Bronnit y Stenning sostienen, por ejemplo, que la discrecionalidad policial es un aspecto ubicuo y legítimo del policiamiento contemporáneo, aunque sus límites y alcances han sido

${ }^{10}$ Confróntese, ERICSON (1989), pp. 205-226; REINER (2000), passim; MONJARDET (2010), passim; BRONITT, (2011), pp. 319-332.

${ }^{11}$ MONJARDET (2010), p. 46.

12 BINDER (2002), passim; ARSLANIÁN (2011), passim; CEJA (2005), passim; DUCE (2005), passim; CELS (2004), passim; DIAZ (2017), pp. 1-19.

${ }^{13}$ En Argentina, la justicia federal y seis provincias aún conservan sistemas inquisitivos morigerados, DIAZ (2017), passim. Actualmente se está promoviendo la reforma acusatoria del sistema judicial federal. Ahora bien, según Bergman y Langer, la evidencia empírica no muestra un mejor desempeño de parte de los fiscales (con respecto a los jueces de instrucción) en las investigaciones criminales. Para el caso más importante de reforma en Argentina, véase BERGMAN y LANGER (2015), pp. 51-80.

${ }^{14}$ SAIN (2002), passim; SAIN (2007), passim; DEWEY (2015), passim; RODRIGUEZ (2018), pp. 1-27.

${ }^{15}$ ANDERSEN (2002), passim; SAIN (2002), passim; SAIN (2007), passim. 
poco estudiados. ${ }^{16}$ Monjardet y Marenin explican que la discrecionalidad policial refiere al discernimiento, a la aplicación de un juicio sobre lo que es oportuno hacer, cuándo y cómo hacerlo; es el criterio dado por el ejercicio de la profesión o el trabajo calificado. ${ }^{17}$ Bianciotto $^{18}$ agrega que ciertos criterios entendidos como específicamente policiales son coincidentes con otros criterios dados por instituciones judiciales, la sociedad civil e inclusive los medios de comunicación.

De este campo experto, y para nuestro trabajo, nos parecen especialmente orientadores los aportes de Monjardet. Dicho autor explica que la policía contiene por lo menos tres modos de producción policiales, con objetivos y discrecionalidades que deben diferenciarse y no se comprenden como negativos. ${ }^{19}$ También plantea la polémica sobre la naturaleza exacta de la competencia policial, sobre qué se basa, cómo se adquiere y si se puede medir. De acuerdo con este autor, por un lado están quienes entienden que la competencia policial es producida por el encuentro entre ciertas cualidades personales del individuo y un abanico lo más amplio posible de experiencias vivenciales. Aquí dicha competencia es esencialmente subjetiva (relacionada con la persona y sus rasgos de carácter propios) y empírica (acumulada a lo largo de acontecimientos que constituyen precedentes cuya evaluación fracaso/éxito-ensayo/error-permite la elaboración progresiva de un saber operatorio eficaz). El policía competente es el que tiene antigüedad, experiencia en el terreno, que fue aprendiendo sobre la marcha, dado que los conocimientos formales por sí solos no son garantía de competencia y se rechaza la posibilidad de protocolizar o transcribir en manuales las "recetas" aprendidas.

Por otro lado, están aquellos que consideran que el saber-hacer policial está basado sobre conocimientos formales, en el dominio de técnicas precisas objetivas, transmisibles, fundadas en códigos, que permitirían minimizar precisamente la influencia de las cualidades personales y paliar la desigualdad de experiencias individuales. En esta visión, la competencia policial es objetiva (independiente de las idiosincrasias) y teórica (no se trata de extrapolar a partir de experiencias singulares, sino, por el contrario, de un marco definido de manera general que se aplica a los acontecimientos particulares). Los elementos esenciales de este marco son proporcionados por los códigos vigentes: código de procedimiento penal, reglas de tránsito, leyes, reglamentos administrativos, documentos internos, circulares de servicio, etc. El policía calificado es el que posee un profundo conocimiento de este corpus y de las técnicas de intervención.

\footnotetext{
${ }^{16}$ BRONITT y STENNING (2011), passim

${ }^{17}$ MARENIN (2007), pp. 86-88. Para MONJARDET (2010), pp. 50-57, se trata de un proceso de "selección", mediante el cual el agente en su labor cotidiana elige cuáles tareas cumplirá, de qué modo y en qué orden, ya que las mismas no están enunciadas y prescritas de antemano.

${ }^{18}$ BIANCIOTTO (2013), passim.

${ }^{19}$ Estos modos son denominados por el autor como: el orden político, la represión del crimen y la seguridad pública, MONJARDET (2010), passim. La función de investigación criminal que alimenta a la justicia es el ejemplo emblemático del segundo modo de producción (p. 164).
} 
Tabla 1. Modelos de la competencia policial

\begin{tabular}{|l|l|l|}
\hline \multicolumn{1}{|c|}{ Naturaleza } & \multicolumn{1}{|c|}{ Artesanal } & \multicolumn{1}{c|}{ Profesional-técnica } \\
\hline Basamento & $\begin{array}{l}\text { Subjetiva y empírica } \\
\text { Cualidades personales y } \\
\text { experiencias vivenciales } \\
\text { individuales. }\end{array}$ & $\begin{array}{l}\text { Objetiva y teórica } \\
\text { objetivas y transmisibles. }\end{array}$ \\
\hline $\begin{array}{l}\text { Construcción del saber- } \\
\text { hacer eficaz }\end{array}$ & $\begin{array}{l}\text { A partir de la acumulación de } \\
\text { acontecimientos y sus } \\
\text { evaluaciones (fracaso/éxito- } \\
\text { ensayo/error). }\end{array}$ & $\begin{array}{l}\text { Mediante la aplicación de un } \\
\text { marco general a eventos } \\
\text { particulares. }\end{array}$ \\
\hline Elementos valorados & $\begin{array}{l}\text { Experiencia, antigüedad, } \\
\text { aprendizaje en terreno. }\end{array}$ & $\begin{array}{l}\text { Conocimientos formales, } \\
\text { códigos, manuales, protocolos. }\end{array}$ \\
\hline
\end{tabular}

Fuente: Elaboración propia en base a MONJARDET (2010), pp. 137-145.

Con este recorrido de la literatura experta, no exento de tensiones, nuestro estudio se propone indagar en el vínculo entre la discrecionalidad policial y las investigaciones criminales. Nos preguntamos sobre el espacio de la discrecionalidad policial en la investigación de los delitos; sobre los intereses, saberes y destrezas que se ponen en juego; sobre cómo se generan estos saberes y destrezas y sobre cómo se mide su eficacia.

\section{Decisiones metodológicas}

El objetivo general del estudio es examinar el vínculo entre la discrecionalidad policial y la investigación criminal, a partir de un diseño de investigación exploratorio basado en el estudio de caso con intención comparativa. ${ }^{20}$ Si bien la Policía de Seguridad Aeroportuaria es una fuerza de menores dimensiones que las restantes policías y fuerzas de seguridad federales argentinas, su agrupamiento investigativo opera bajo la misma lógica que las restantes. $^{21}$ Debido a que se trata de una policía que cumple funciones específicas y focalizadas en cierta criminalidad, su trabajo es asimilable al de las demás fuerzas que intervienen en el nivel federal, diferenciándose de los cuerpos policiales subnacionales que lidian con la delincuencia común y cuentan con mayores flujos de casos y efectiva labor de "calle". 22 Adicionalmente, nuestra posición como investigadores-docentes dentro de la fuerza estudiada nos permitió recopilar y analizar información de difícil acceso para

\footnotetext{
${ }^{20}$ Seguimos en esta elección las recomendaciones de GEORGE y BENNETT (2005), pp. 67-69, quienes subrayan la necesidad de ser cuidadosos en la elección de los casos y el diseño de la investigación, de modo de garantizar: a) una mayor comprensión de los fenómenos de interés, a partir de la correcta identificación de la "clase" de eventos; y b) la futura comparación con casos asimilables, a partir de la apropiada definición de objetivos y preguntas.

${ }^{21}$ La organización de la seguridad interior en Argentina está determinada en gran medida por la estructura federal del país. El Estado argentino está constituido por un gobierno nacional y por 24 gobiernos subnacionales con sus propias policías. El gobierno nacional cuenta con dos policías y dos fuerzas de seguridad para garantizar la dimensión federal de la seguridad interior: la policía federal argentina, la policía de seguridad aeroportuaria, la gendarmería nacional y la prefectura naval. Las fuerzas federales argentinas están abocadas principalmente a la persecución de los delitos federales, aunque además pueden investigar ciertos delitos comunes, principalmente dentro del ámbito jurisdiccional de cada una. Las policías provinciales, por su parte, intervienen e interactúan con la justicia en el nivel ordinario.

${ }^{22}$ Agradecemos las observaciones de un revisor anónimo respecto de este punto.
} 
especialistas externos. En efecto, esperamos que nuestro estudio de caso aporte información novedosa y relevante para caracterizar a la discrecionalidad policial en la investigación criminal más allá del caso de la PSA, esperando contribuir al debate general sobre cómo mejorar la organización y el accionar de las fuerzas policiales y de seguridad a nivel federal en dicha tarea.

El diseño de investigación combinó técnicas cuantitativas y cualitativas en la recolección y análisis de la información, recurriendo a una variedad de fuentes, procurando evitar sesgos en la selección y el análisis de los datos. ${ }^{23}$ El relevamiento de información fue llevado a cabo de la siguiente manera. En primer lugar, se examinaron diversos materiales documentales incluyendo legislación y protocolos, ${ }^{24}$ manuales de procedimiento y cualquier otro documento que tuviera incidencia en el ordenamiento de la investigación criminal en Argentina y en la PSA. Asimismo, se relevaron los recursos humanos con que cuenta la fuerza para el desarrollo de las tareas de investigación.

En segundo lugar, se generó una base de datos con información actualizada referente a las causas de investigación en las que interviene la fuerza. Esta base contiene información sobre: origen de la causa (interno-externo); problemática delictual; fecha de inicio (en la PSA); unidad investigativa; juzgado en que se encuentra radicada la causa; provincia; jurisdicción judicial. Esta base incluye datos del período 2006-2016. ${ }^{25}$ El recorte temporal abarca la primera década de existencia de la fuerza y permite observar su evolución y tendencias en materia de investigación policial de delitos complejos.

Por último, para el examen del accionar de la PSA en materia de investigación criminal, se llevaron a cabo entrevistas semiestructuradas a integrantes de la policía, complementadas con otras a funcionarios del ministerio público y el poder judicial que tienen contacto directo con estas investigaciones. Nuestro diseño pretendió capturar en primer lugar la perspectiva de los actores implicados en los procesos que recomienda razonablemente Frederic, ${ }^{26}$ examinando luego las continuidades y discontinuidades entre sus saberes y valores y el entramado legal de la persecución penal en Argentina. Un potencial problema con esta técnica consiste en el riesgo de que las respuestas de los entrevistados estén sesgadas y no sean completamente honestas. ${ }^{27}$ La garantía de confidencialidad de las entrevistas (mediante la firma de acuerdos de confidencialidad) y el diseño de la muestra contemplaron esta situación y contribuyeron a sortear esta dificultad.

\footnotetext{
${ }^{23}$ EPSTEIN y KING (2002), passim.

${ }^{24}$ Código Penal de la Nación; Ley N²3.737 de Estupefacientes; Ley N 22.415 Código Aduanero; Código Procesal Penal Nacional y provinciales; Ley $N^{\circ} 26.102$ de Seguridad Aeroportuaria; Ley $\mathrm{N}^{\circ} 25.246$ de Lavado de Dinero; Ley $N^{\circ} 27.126$ Creación de la Agencia Federal de Inteligencia; Protocolos del Ministerio de Seguridad (allanamientos, requisas, contrabando de estupefacientes, recolección de pruebas en ciberdelito, preservación de la escena del hecho y sus pruebas); Protocolos Generales de Actuación de la PSA; entre otras. ${ }^{25}$ La base cuenta con datos actualizados al 30/11/2016 inclusive.

${ }^{26}$ FREDERIC (2008), passim.

27 El problema de la deseabilidad social es una dificultad repetida y fundamental en las investigaciones sociales en general, y particularmente en aquellas donde el interlocutor forma parte de la misma institución y/o que tratan información delicada como la vinculada a las prácticas de investigación criminal (Confróntese EDWARDS (1957), passim).
} 
La selección de la muestra fue no probabilística, a partir del muestreo deliberado o crítico. Los testimonios utilizados para este artículo fueron relevados entre agosto de 2016 y enero de 2019. El listado de 36 entrevistados incluye personal de: unidades regionales de seguridad aeroportuaria, unidades operacionales de control del narcotráfico y delitos complejos, divisiones de inteligencia criminal aeroportuaria, unidades operacionales de seguridad preventiva, juzgados federales, en lo penal económico y en lo criminal correccional, fiscalías federales, procuradurías y unidades fiscales especializadas. ${ }^{28}$ Las entrevistas fueron grabadas para su posterior transcripción. La codificación, procesamiento y análisis de la información fue efectuado utilizando el software Atlas.ti. Como muestra teórica, las principales estrategias de validación de la información generada en las entrevistas han sido la redundancia y la triangulación con otro tipo de datos (por ejemplo, la base de causas).

\section{Resultados}

\subsection{La organización de la investigación criminal en la PSA}

La investigación de delitos se define comúnmente como el proceso por el cual se busca descubrir al/os autor/es de un delito mediante la reunión de hechos (o pruebas), si bien también puede suponer la determinación, ante todo, de si se ha cometido o no un delito. ${ }^{29}$ La tarea policial investigativa tiene la finalidad de aportar evidencias -a partir de indicios de un suceso- a las autoridades judiciales para que, posteriormente, puedan convertirse en prueba. El Código Procesal Penal de la Nación Argentina establece que:

"La policía o las fuerzas de seguridad deberán investigar, por iniciativa propia, en virtud de denuncia o por orden de autoridad competente, los delitos de acción pública, impedir que los hechos cometidos sean llevados a consecuencias ulteriores, individualizar a los culpables y reunir las pruebas para dar base a la acusación..."30

En Argentina, una investigación criminal puede comenzar por intervención policial -a través de la prevención-, o a través de denuncias en su sede, ante el juez o ante el Ministerio Público Fiscal $^{31}$. En el caso de la PSA, la investigación criminal es función principal del

\footnotetext{
${ }^{28}$ La distribución de los entrevistados es la siguiente: Seguridad Compleja: 14 (39\%); Seguridad Preventiva: 13 (36\%); Inteligencia Criminal: 2 (6\%); Poder Judicial: 4 (11\%); Ministerio Público: 3 (8\%). La mayor parte del trabajo de campo fue realizada en Ezeiza, CABA y Rosario, dada la relevancia de estas áreas en la labor investigativa de la PSA así como por su accesibilidad geográfica.

${ }^{29}$ UNODC (2010), passim.

${ }^{30}$ Código Procesal Penal de la Nación, art. 183.

${ }^{31}$ La organización del sistema de justicia responde al carácter federal del Estado nacional. La justicia federal tiene competencia en todo el país, llevando adelante la instrucción de ciertos delitos específicos: estupefacientes, crímenes de lesa humanidad, trata de personas, lavado de activos, corrupción, contrabando, evasión fiscal y otros delitos que afectan a la renta y a la seguridad de la nación (Código Procesal Penal, art. 33). Cada una de las provincias, por su parte, cuenta con una justicia provincial que entiende en el tratamiento de los delitos comunes (también denominada justicia ordinaria), con sus propios órganos judiciales y legislación procesal.
} 
agrupamiento seguridad compleja ${ }^{32}$ a través de sus unidades operacionales; tanto para los casos que se inician dentro del ámbito aeroportuario como aquellos externos al mismo, de acuerdo con los requerimientos efectuados por las autoridades judiciales.

Existen cinco Unidades Operacionales de Control del Narcotráfico y el Delito Complejo (UOCNyDC) distribuidas en todo el país, dependientes de las Unidades Regionales de Seguridad Aeroportuaria (URSA). Las URSA son las instancias medias de la estructura operacional del sistema policial; en ellas se descentraliza la gestión de la seguridad aeroportuaria preventiva y compleja. ${ }^{33}$ A las UOCNyDC regionales se suman dos unidades de seguridad compleja que dependen directamente del Centro de Análisis, Comando y Control (CEAC) y tienen jurisdicción federal: la UOCNyDC Central y la Unidad Operacional Antiterrorista y de Control de Actividades que atenten contra los Poderes Públicos y el Orden Constitucional (UOA). La figura 1 muestra la ubicación de cada uno de estos elementos en la estructura organizacional de manera estilizada.

\section{Figura 1. Estructura operacional de la PSA}

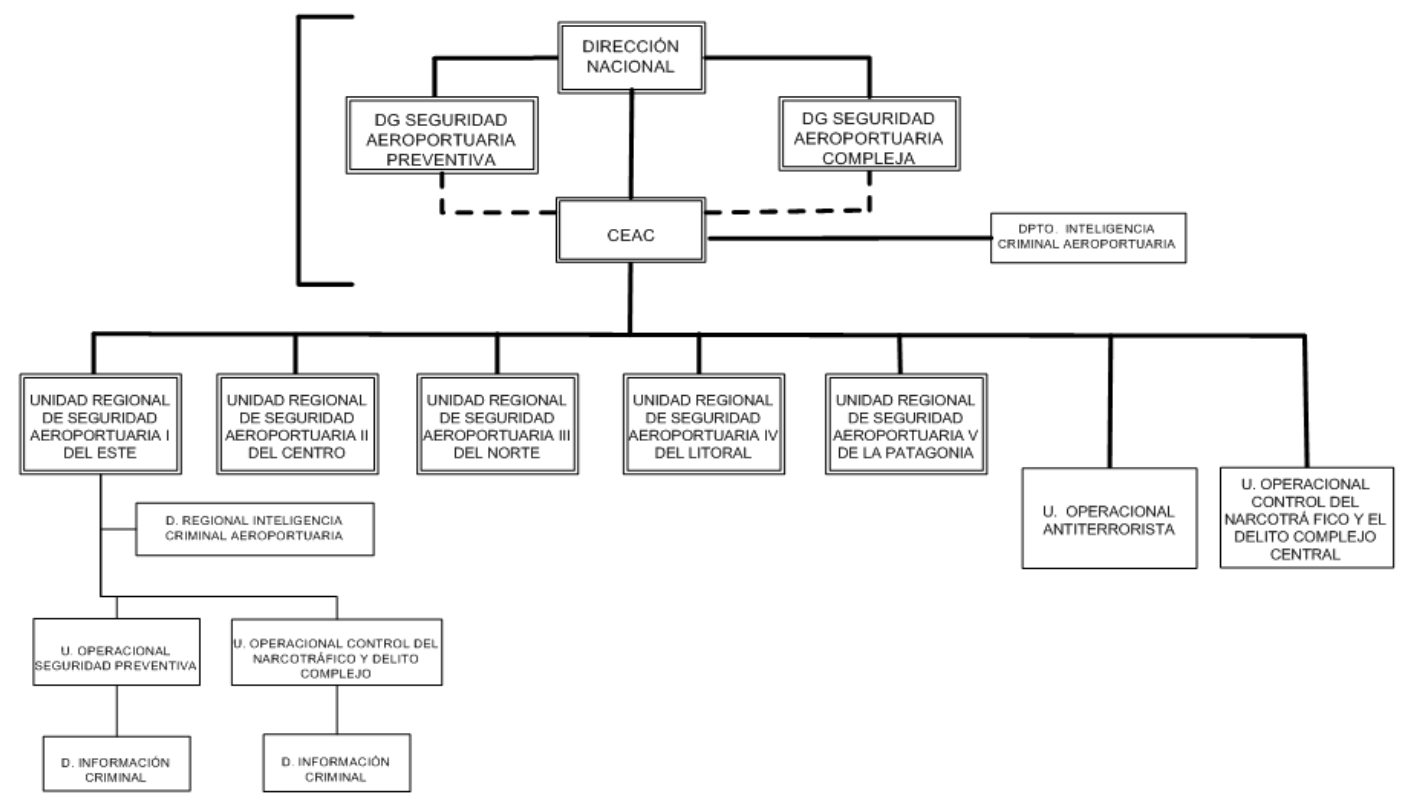

Fuente: Elaboración propia en base a Res. MSN N 1015/1012 y disposiciones internas complementarias.

\footnotetext{
${ }^{32}$ La carrera de los oficiales en esta fuerza está estructurada en dos agrupamientos: seguridad preventiva y seguridad compleja, en concordancia con los dos elementos principales de la misión institucional (Ley $\mathrm{N}^{\circ}$ 26.102, art. 43).

${ }^{33}$ Las unidades regionales están conformadas del siguiente modo: I del Este (Buenos Aires); II del Centro (Córdoba, Mendoza, San Luis, San Juan, La Pampa); III del Norte (Salta, Tucumán, Santiago del Estero, Jujuy, La Rioja, Catamarca); IV del Litoral (Misiones, Santa Fe, Entre Ríos, Corrientes, Formosa, Chaco); y V de la Patagonia (Río Negro, Neuquén, Chubut, Santa Cruz, Tierra del Fuego). Las URSA agrupan, asimismo, a las Unidades Operacionales de Seguridad Preventiva (UOSP), que son las unidades operativas terminales dentro de la estructura operacional de la PSA, encargadas de la labor de seguridad preventiva en los aeropuertos que integran el Sistema Nacional de Aeropuertos. El despliegue operacional preventivo puede consultarse en https://www.argentina.gob.ar/policia-aeroportuaria/la-psa-en-el-pais. El despliegue territorial completo de la PSA está establecido en la Res. MSN N ${ }^{\circ}$ 1015/2012 y modificatorias.
} 


\section{Aeroportuaria en Argentina".}

El circuito de la investigación criminal (policial y penal) en el ámbito aeroportuario es ilustrado en la figura 2. Ante la detección o denuncia de un delito, las unidades operacionales de seguridad preventiva se ponen en contacto con el juzgado de turno, quien puede ordenar la ejecución de ciertas medidas (tales como: registro fílmico, declaraciones testimoniales, secuestro de elementos, reactivos de campo -en casos de narcotráfico-). Conforme los resultados de dichas medidas, se procede a la confección del acta de procedimiento y posterior sumario. En caso de corresponder, también al traslado de detenidos y elementos o sustancias secuestradas (si las hubiera). Luego de la elevación de sumario al juzgado, éste puede determinar la asignación de tareas investigativas a las unidades operacionales de seguridad compleja, quienes a su vez enviarán un informe al juzgado con el reporte de la labor realizada y los correspondientes hallazgos. El juzgado, de considerarlo conveniente, puede ordenar nuevas tareas investigativas, y así sucesivamente. El envío de un oficio judicial que ordene tareas investigativas a las unidades operacionales complejas también puede dar inicio a nuevas investigaciones.

La figura muestra el circuito completo (para un caso iniciado en el ámbito aeroportuario preventivo). La línea de puntos señala la división entre las causas de origen interno (preventivo) y externo (cuando la investigación no comienza en el aeropuerto sino que se origina por mandato judicial). De la figura se desprende que en todos los casos la intervención del juzgado es necesaria para que la unidad de seguridad compleja inicie las tareas investigativas.

Figura 2. Circuito de la investigación policial y penal en la PSA

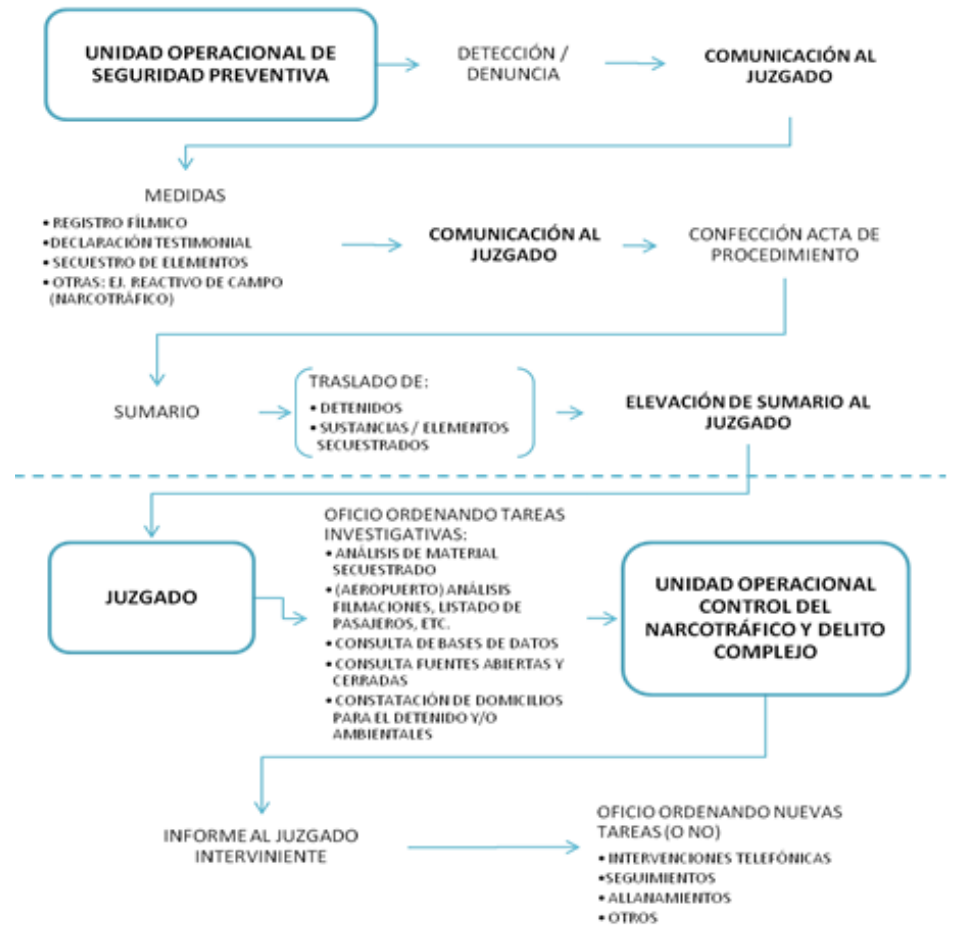

Fuente: Elaboración propia 


\section{Polít. Crim. Vol. 15, № 29 (Julio 2020), Art. 1, pp. 25-46 [http://politcrim.com/wp-content/uploads/2020/01/Vol15N29A1.pdf]}

\subsection{El espacio de la discrecionalidad policial en la investigación criminal}

Más arriba mencionamos estudios que enfatizan que la policía combina varios agrupamientos, lo cual afecta distintos modos de discrecionalidad policial. ${ }^{34} \mathrm{~A}$ diferencia de los agrupamientos centrados en la prevención urbana que trabajan fundamentalmente a partir de la demanda ciudadana y el acontecimiento, con pocas instrucciones específicas, los agrupamientos de investigación criminal suelen tener un control y una reglamentación mayor, que proviene especialmente de la rama penal de la justicia. ${ }^{35}$

El análisis de las causas investigadas por la PSA y de los testimonios de policías y operadores judiciales entrevistados apoya esta perspectiva, en la medida en que muestra que los jueces y/o los fiscales (según el Código Procesal Penal sea más o menos acusatorio) tienen un rol importante en cuánto, qué y cómo investigan los integrantes de la fuerza. En primer lugar, los magistrados tienen la facultad de elegir entre las fuerzas a sus auxiliares para la investigación criminal. Los operadores judiciales entrevistados explican que a la hora de decidir con quiénes trabajar suelen ponderar razones como: i) la experiencia en el caso detectado o el tipo de delito investigado (por ejemplo, delitos económicos, narcotráfico, trata de personas, secuestros); ii) los recursos humanos y técnicos disponibles en las fuerzas; iii) el lazo de confianza construido en el tiempo.

El peso de la voluntad de los operadores judiciales en el volumen de trabajo investigativo que realiza la PSA aparece en los testimonios de policías y funcionarios. Los entrevistados consideran que las investigaciones criminales en la PSA se multiplicaron en la última década fundamentalmente porque los magistrados comenzaron a conocer y confiar en el trabajo de la fuerza como auxiliar de justicia:

"Cuando se sancionó la ley [N² 26.102 de Seguridad Aeroportuaria], no nos conocía nadie. Íbamos a pedir trabajo a las fiscalías... se empezó así y después tuvimos que decir "por favor, no nos den más trabajo". 36

"A medida que fueron pasando los años, los juzgados nos fueron conociendo, fueron tomando mucha confianza en la PSA y actualmente trabajamos más causas que vienen desde afuera, de los diferentes juzgados, de todos los delitos, no solamente narcotráfico, que las propias generadas del turno de prevención". ${ }^{37}$

El análisis de las causas investigadas por la PSA por año comprueba esta tendencia creciente. El gráfico 1 muestra la evolución anual (en número de veces) del total de causas entre 2006 y 2016 en la PSA, tomando el año 2006 como base $(=1)^{38}$. Desde 2011 en adelante, en promedio la PSA participó 15 veces más en investigaciones penales que en

\footnotetext{
${ }^{34}$ BRODEUR (2011), passim; MONJARDET (2010), passim.

${ }^{35}$ MONJARDET (2010), passim.

${ }^{36}$ Entrevistado $\mathrm{N}^{\circ} 28$ - PSA, 18/08/2016. Los testimonios provienen tanto de hombres como de mujeres, aunque la prevalencia fue masculina. Se optó por utilizar el genérico masculino, a fin de evitar la identificación y garantizar el anonimato de los/as entrevistados/as. Las referencias institucionales son: Policía de Seguridad Aeroportuaria (PSA); Poder Judicial (PJ); Ministerio Público Fiscal (MPF).

${ }^{37}$ Entrevistado $N^{\circ} 30$ - PSA, 28/04/2017.

${ }^{38}$ Debido a que se trata de estadísticas basadas en información criminal, optamos por mostrar tendencias y no valores absolutos, atendiendo a la sensibilidad de los datos presentados.
} 
2006. A este dato se suma que esta fuerza se destaca por la gran cantidad de investigaciones de origen externo a su ámbito de actuación preventiva. El $40 \%$ de las investigaciones en el período ha tenido origen interno (con intervención preventiva), mientras que el restante $60 \%$ ha comenzado de modo externo (por mandato judicial, sin intervención preventiva). Este guarismo aumenta si consideramos sólo el último lustro: entre 2012 y 2016 -inclusivelas causas de origen externo representan en promedio el $70 \%$ del total.

Gráfico 1. Evolución anual de delitos investigados en la PSA (2006-2016)

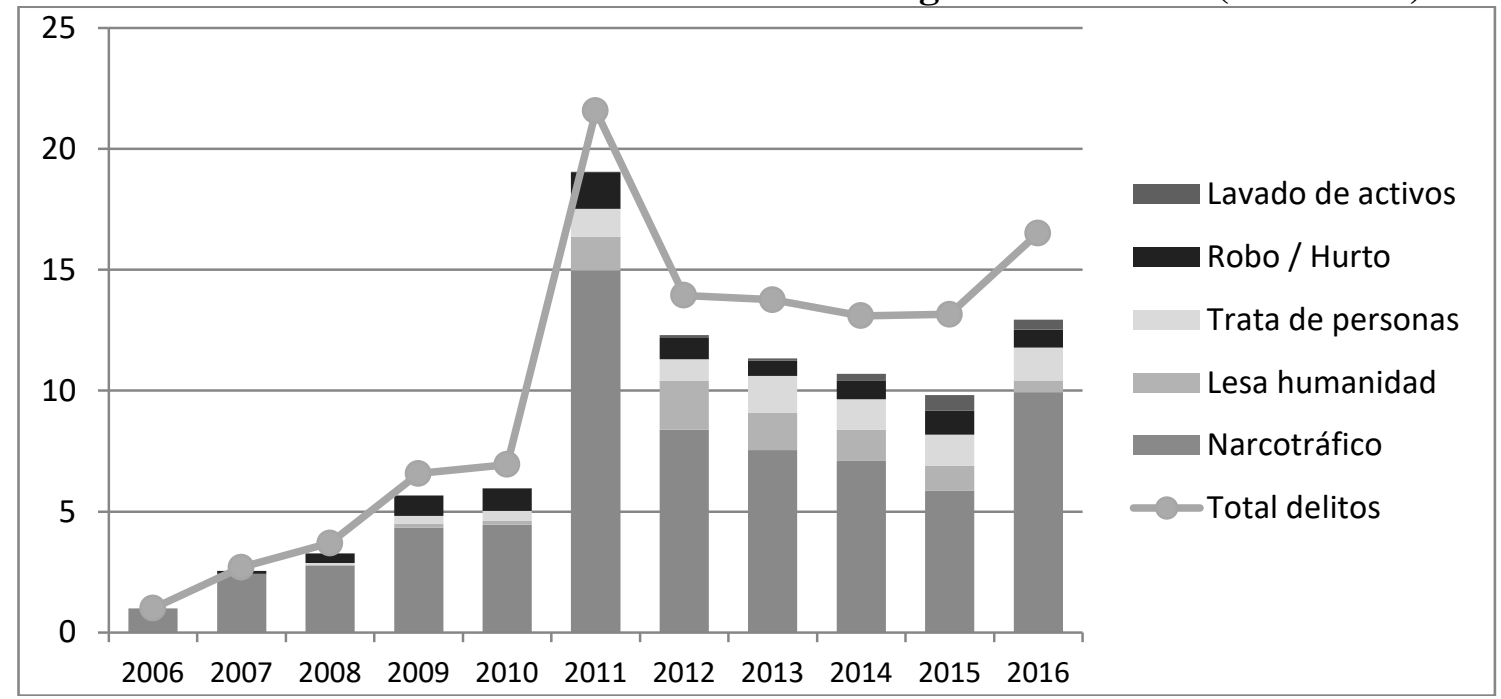

Fuente: Elaboración propia. Año base=2006.

La información recabada tanto en las entrevistas como en la base de causas investigadas por la PSA indica que los jueces no sólo influyen en cuánto investigan las policías, sino también qué delitos investigan. Por ejemplo, los testimonios relevados dejan entrever que los funcionarios judiciales dictan instrucciones a los policías sobre la orientación y el contenido de las investigaciones, influidos a su vez por las demandas políticas y de la opinión pública: ${ }^{39}$

"Hay presiones mediáticas, la repetición de un hecho determinado en un medio genera que la gente interprete que lo que se está haciendo no es lo que corresponde. Y [presiones] políticas también. Hoy por hoy, que el presidente diga que no tiene que estar preso el carnicero, ${ }^{40}$ obviamente, al juez o fiscal que tenga que resolver le genera presión". ${ }^{41}$

\footnotetext{
39 Este accionar estratégico de los jueces y fiscales frente a los lineamientos de la agenda pública puede asociarse al análisis de Helmke para el caso de los ministros de la Corte Suprema de Justicia en Argentina. Esta autora nota que los magistrados acompañan las preferencias del ejecutivo mientras este se mantiene fuerte. Una vez que el gobierno de turno empieza a perder poder, los jueces comienzan a tener incentivos para aumentar sus dictámenes anti-gubernamentales, de modo de distanciarse de un gobierno debilitado; HELMKE (2002), pp. 291-303. Una revisión actualizada de la literatura sobre política judicial en América Latina puede consultarse en INGRAM (2015), pp. 250-260.

${ }^{40}$ En referencia al mediático caso del "carnicero", Daniel Oyarzún, quien atropelló y mató a un ladrón que lo había asaltado en su comercio del partido bonaerense de Zárate, en septiembre de 2016. Al respecto, el Presidente M. Macri había declarado que "debería estar con su familia, tranquilo, tratando de reflexionar en
} 
"Venimos de 10 años de un gobierno que quiso manejar las cosas con la parte de 'Justicia Legitima'. ${ }^{42}$ Acá lo único que servía era hacer lesa humanidad, todo el mundo haciendo lesa humanidad. Con el narcotráfico, el terrorismo y todas esas cosas no pasaba nada. Había que hacer lesa humanidad porque el gobierno quería hacer lesa humanidad. Ahora viene este gobierno y cambia". ${ }^{3}$

Si examinamos la proporción de delitos investigados por año en la PSA respecto del total de causas, observamos tendencias fluctuantes a lo largo del tiempo. Estas tendencias parecen ajustarse mejor a lo dicho por los entrevistados sobre el accionar estratégico de jueces y fiscales que al enfoque delegativo desarrollado en el estado del arte. Por ejemplo, las investigaciones de la PSA en materia de crímenes de lesa humanidad fueron incrementándose desde 2010 y con niveles relativamente estables hasta 2015 (10\% promedio), decreciendo considerablemente en 2016 (3\%). Por otra parte, la instrucción de causas vinculadas al narcotráfico, que había venido registrando una caída sostenida desde 2012 (-6\% promedio), experimentó un elevado aumento durante 2016, tanto en términos proporcionales como absolutos. ${ }^{44}$

\section{Gráfico 2. Proporción de causas investigadas según delitos (siguiente página)}

todo lo que pasó" ("Macri, sobre el carnicero que mató al ladrón: "Debería estar con su familia"”, CLARÍN 15/09/2016).

${ }^{41}$ Entrevistado $\mathrm{N}^{\circ} 9$ - PJ, 07/10/2016.

42 Justicia Legítima es una asociación civil que se define como un conjunto de personas comprometidas en trabajar de forma activa en la democratización de los poderes judiciales de la Argentina. Para sus críticos, es una agrupación de jueces y fiscales afines con el gobierno kirchnerista (confróntese. "Justicia Legítima es una asociación civil, no es una asociación ilícita", PERFIL 06/08/2016).

${ }^{43}$ Entrevistado $\mathrm{N}^{\circ} 33$ - PSA, 09/01/2019

${ }^{44}$ Estas variaciones son consistentes con cambios en las demandas del gobierno y la opinión pública respecto a qué debe criminalizarse. El período entre 2010 y 2015 se caracterizó por la hegemonía del discurso progresista en materia de seguridad ciudadana en la agenda pública, del estilo de las propugnadas por las principales organizaciones de derechos humanos del país (COSTANTINO (2016), passim). En contraste, con el cambio en el color político del gobierno nacional, la nueva gestión adhirió a un discurso sobre la seguridad más vinculado a políticas de derecha (Mauricio Macri -Coalición Cambiemos/PRO- asumió la presidencia el 10/12/2015, luego de 12 años de gestiones "kirchneristas". Confróntese, COSTANTINO y GUTIÉRREZ (2017), passim, siendo uno de los ejes de campaña y luego de gestión la lucha contra el narcotráfico (confróntese, "Mauricio Macri lanzó el plan "Argentina sin narcotráfico": "Este compromiso no va a quedar en una foto"”, LA NACIÓN 30/08/2016). 


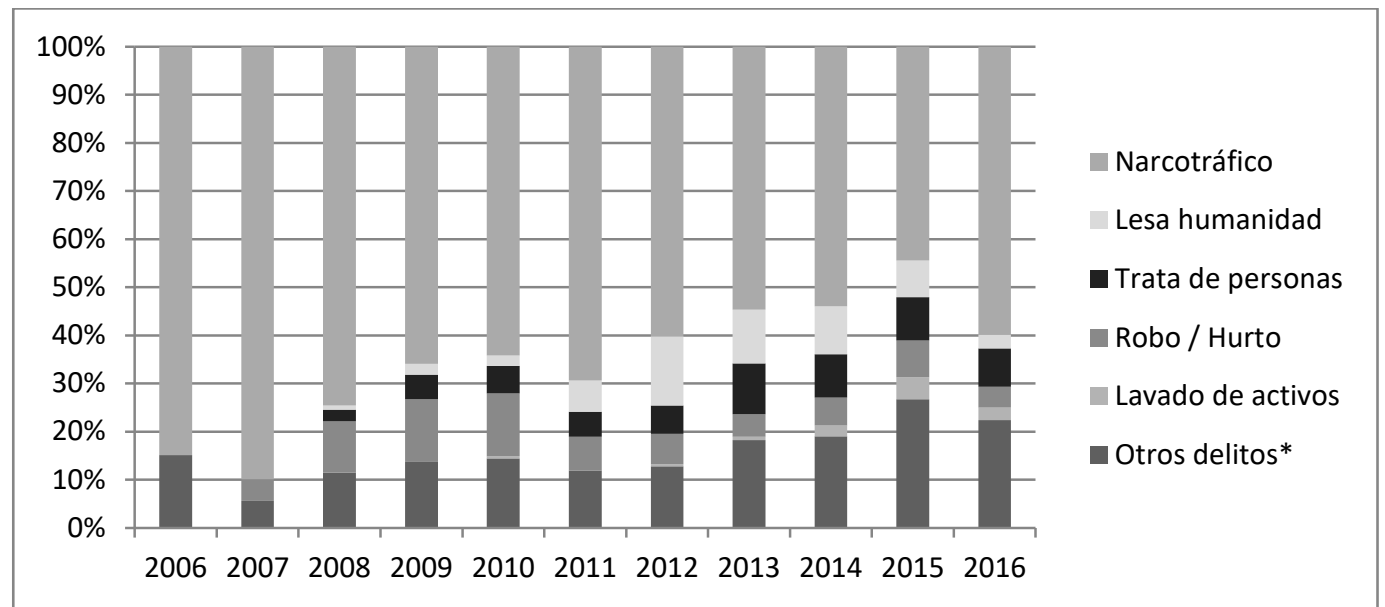

Fuente: Elaboración propia. *Otros delitos incluye: contra la libertad, contra la administración pública, falsificaciones, otros. Ninguno de estos tipos delictivos alcanza por sí mismo el 5\% de las investigaciones.

Ahora bien, los entrevistados acuerdan (entre ellos y en consonancia con lo predicado por la literatura) en que los policías, formalmente auxiliares de justicia, tienen un espacio de discrecionalidad en la investigación criminal, al punto que pueden proponer la ejecución de ciertas tareas investigativas a los operadores judiciales, por ejemplo, nuevas escuchas telefónicas o una orden de allanamiento.

"Nosotros informamos y le proponemos al fiscal. (...) Vos le podés decir que surgió un nuevo teléfono y que sería conveniente intervenirlo y así, sucesivamente... Generalmente la justicia no puede quedarse con los brazos cruzados. Más cuando vos lo plasmaste en los papeles..."45

Los operadores judiciales apoyan la existencia y la necesidad de este intercambio para el desarrollo óptimo de la persecución penal, por ejemplo en la vigilancia controlada de actividades de narcotráfico.

"Nosotros estamos en una comunicación constante con las fuerzas de seguridad, en cuanto a cómo se realizan los trabajos y el feedback por parte de las fuerzas de seguridad de qué es lo que está obteniendo. (...) El análisis de la policía nos sirve para saber [si] estamos en condiciones de realizar un procedimiento en el cual, a modo de ejemplo, yo pueda detener un camión ingresando a la capital o es riesgoso porque lo puedo perder, [si] tenemos la capacidad operativa para seguir un transporte desde el norte a la capital". ${ }^{6}$

Esta mirada del poder judicial y el ministerio público coloca el espacio de la discrecionalidad de los investigadores policiales, en general, no como un problema sino más bien como una solución para el desarrollo efectivo de las investigaciones. "La realidad es que el tipo que está en la calle, el tipo que mira, el tipo que hace el relevamiento, es el personal que está ahí', 47

\footnotetext{
${ }^{45}$ Entrevistados $N^{\circ} 5$ y 6 - PSA, 16/09/2016.

${ }^{46}$ Entrevistado $N^{\circ} 25-\mathrm{PJ}, 07 / 12 / 2016$.

${ }^{47}$ Entrevistado N ${ }^{\circ} 10-$ PJ, 07/10/2016.
} 
Sin perjuicio de lo anterior, los funcionarios judiciales también manifiestan estar atentos para no ser embaucados con causas contaminadas o vinculadas a prácticas ilegales. Los entrevistados reconocen que existen segmentos de las policías corrompidos por los negocios criminales (como el narcotráfico o la trata de personas), además de direccionamientos políticos en causas sensibles como el caso de la AMIA o de Nisman. ${ }^{48}$ Para evitar que se rompa el lazo de confianza con los agentes, los operadores utilizan estrategias o salvaguardias judiciales en el desarrollo de las prácticas investigativas, como presionar con los plazos a las diligencias policiales y/o cambiar de auxiliar de justicia ante resultados irregulares.

En suma, encontramos que la discrecionalidad policial en la investigación criminal está limitada por el rol de jueces y fiscales que afectan cuánto, qué y cómo se investiga. Sin embargo, más allá del cuidado referido por los funcionarios judiciales para no ser engañados con causas "armadas" o prácticas corruptas, existe un espacio de discrecionalidad en la labor policial que se considera necesario para el desarrollo de las investigaciones y se asocia a un saber-hacer profesional. En el siguiente apartado nos detendremos sobre las características de este saber-hacer policial.

\subsection{Entre el arte y la técnica: el saber-hacer del investigador}

Las caracterizaciones que recogimos sobre la discrecionalidad policial entre funcionarios de justicia la asocian a un saber-hacer necesario aunque reconociendo que también puede dar lugar a la contaminación del trabajo por intereses propios e influencias externas. Pero, ¿qué conocimientos y destrezas implican este saber-hacer policial? ¿Cómo se generan? ¿Cómo se mide su eficacia? Recordemos que sobre esta competencia policial, existe la polémica sobre si es un saber más artesanal o más técnico: si se entiende como producido por el encuentro de ciertas cualidades personales del individuo y un abanico lo más amplio posible de experiencias, o por el dominio de técnicas precisas objetivas, transmisibles, basadas en códigos. Dentro de este encuadre, Monjardet asocia el trabajo de persecución del crimen a una organización profesional de las tareas, donde la cualificación se adquiere a partir de saberes técnicos, lo que redunda en experticia. ${ }^{49}$

\footnotetext{
${ }^{48}$ La causa AMIA refiere a uno de los mayores atentados terroristas ocurridos en Argentina, ocurrido el 18 de julio de 1994 frente a la sede porteña de la Asociación Mutual Israelita Argentina (AMIA), que provocó la muerte de 85 personas y dejó más de 300 heridos. La investigación judicial estuvo plagada de sospechas e irregularidades; el primer juicio (2001-2004) reveló un amplio encubrimiento en el que estuvieron incluidos la justicia argentina y los servicios de inteligencia, pero absolvió a todos los acusados. En septiembre de 2004 se creó una fiscalía especial para el caso (Unidad Fiscal AMIA), a cargo del fiscal federal Alberto Nisman. El 18 de enero de 2015, Nisman fue encontrado muerto con un tiro en la cabeza en su vivienda; las hipótesis que aún se evalúan son: suicidio, suicidio inducido o asesinato. Nisman había denunciado a la entonces Presidenta Cristina F. Kirchner por presunto encubrimiento del atentado a la AMIA a través de un memorándum de entendimiento firmado con Irán y al día siguiente de su muerte debía concurrir a la cámara de diputados a dar testimonio en relación con esta investigación.

${ }^{49}$ Confróntese Tabla 1, ut supra. En cambio, el trabajo policial de seguridad pública (prevención) se asocia con una organización del trabajo artesanal, donde el modo de la cualificación es por la experiencia, lo que redunda en la capacidad de discernimiento. MONJARDET (2010) p. 165.
} 
En nuestro estudio sobre el trabajo policial del agrupamiento investigativo de la PSA, encontramos que el saber hacer del investigador contiene saberes técnicos, pero el elemento artesanal sigue siendo muy importante. En efecto, un primer conjunto de competencias necesarias para los integrantes del agrupamiento investigativo refiere al conocimiento de las normas y del lenguaje que hacen específicamente a la investigación criminal, sumado a la a la necesidad de ser capaces de volcar en los informes y oficios judiciales las tareas y hallazgos realizados.

"Lo fundamental es la capacitación, debemos capacitarnos todo el tiempo, actualizarnos todo el tiempo, con charlas de debate, coloquios. La educación que tiene uno se vuelca y se transmite al Tribunal, porque, en definitiva -y aquí está la situaciónlo que hace el secretario, el juez, es regirse por lo que nosotros le informamos. Lo que está en el expediente es lo que el juez toma como cierto. (...) Por eso es muy importante un secreto que nosotros tenemos en nuestra profesión, que es saber volcar muy bien la información que vamos recabando por distintos medios". ${ }^{50}$

Concordamos con Monjardet en que la labor de investigación tiene cierta especificidad técnica-profesional. Para desarrollar la persecución penal deben dominar los códigos y poder argumentar con magistrados. Los requerimientos judiciales demandan tareas simples como la consulta de bases de datos (abiertas y cerradas) y la búsqueda en redes sociales, hasta labores más complejas y exigentes como escuchas telefónicas y allanamientos. Sin embargo, el trabajo en la calle de los investigadores abre un abanico amplio de posibles experiencias, para los cuales se requieren ciertas cualidades personales del individuo, como: improvisación, flexibilidad, creatividad, iniciativa; cualidades iniciales que con la experiencia en el terreno se desarrollan. Sobre todo en lo que respecta al trabajo en "la calle": vigilando, siguiendo, recabando información de vecinos y conocidos, el oficio de investigador da cuenta de cierta construcción artesanal:

"El trabajo de la calle te lo va a dar la experiencia y salir a la calle todos los días". 51

"Aprendés a prueba y error, aprendés más del error que de otra cosa. Lo que hacemos no sale en ningún libro. Hay improvisación, de hablar, de reuniones de trabajo". 52

"Se usa mucho la creatividad, hay que usar y aprovechar todas las capacidades naturales que tengan las personas". 53

"Cuestión importantísima es la capacidad de repentización y adaptación, es decir, uno en la calle va hablando y por ahí le pregunta algo a tal persona sobre tal o cual cosa. Durante ese diálogo hay quien se bloquea y se queda parado, y se tiene que ir, y hay quienes siguen averiguando". 54

\footnotetext{
${ }^{50}$ Entrevistado $N^{\circ} 28$ - PSA, 18/08/2016.

${ }^{51}$ Entrevistado $N^{\circ} 5$ - PSA, 16/09/2016.

${ }^{52}$ Entrevistado N ${ }^{\circ} 6$ - PSA, 16/09/2016.

${ }^{53}$ Entrevistado N ${ }^{\circ} 7$ - PSA, 16/09/2016.

${ }^{54}$ Entrevistado N ${ }^{\circ} 28$ - PSA, 18/08/2016.
} 
La idea de que las competencias policiales se aprenden y desarrollan en el terreno está muy extendida en las fuerzas, y va más allá de los agrupamientos investigativos. ${ }^{55}$ Sin embargo, en las entrevistas notamos que los aprendizajes en la calle refieren a cosas diferentes en el agrupamiento preventivo y en el investigativo. Tener calle en el agrupamiento preventivo apunta a saber ejercer la autoridad uniformada frente al público en general, previniendo ante todo faltas y accidentes.

"No hay academia, no hay instituto, no hay instalaciones universitarias que te puedan jamás enseñar qué hacer en el momento en que estas sentado en un turno de prevención y escuches un alboroto afuera. No existe. Tenés que levantarte de la silla, ir, ver, observar, sopesar la situación, calmar la situación.... ${ }^{, 56}$

En el agrupamiento investigativo, la calle es el lugar donde uno aprende a mimetizarse con diferentes ambientes, a fin de recabar información para identificar posibles delitos y delincuentes.

"Lo que hace el policía complejo es ir a la calle; a recabar datos, a entrevistarse con gente, todo eso se gana con experiencia". ${ }^{57}$

El aprendizaje artesanal en el agrupamiento preventivo se asocia a lo imprevisible del trato frente a la ciudadanía, la cantidad de tareas diferentes que existen en un turno operativo, las diferentes funciones que requieren las jurisdicciones. Lo artesanal en el agrupamiento investigativo se asocia a lo imprevisible de otra tarea: el hacerse "invisible" o pasar por otra persona, que busca información sensible para la persecución penal.

"El complejo tiene que ser complejo, tiene que tener sangre compleja, tiene que crear, tiene que pensar cómo piensa el delincuente, o qué haría él si se pone del lado del delincuente, ¿cómo haría para zafar...? Tienen que ser creativos". ${ }^{5}$

El trabajo en causas penales complejas requiere finalmente competencias vinculadas a la adaptabilidad política con actores influyentes como los jueces, los políticos y los medios de comunicación.

"Manejar ese tipo de cuestiones, ese tipo de causa, este tipo de situaciones, que se suscitan a veces, [implica] poder manejarlas y tener, como quien dice, una cintura política correcta, para manejarse con los Juzgados, con los Secretarios que a veces son los que aprietan, y acá, digamos, cuesta manejarlo. (...) Solamente nosotros sabemos lo que tenés que poner, jugártela, ir a dar la cara en el Juzgado, las declaraciones, los

\footnotetext{
${ }^{55}$ Confróntese FREDERIC et al. (2008), passim. Este aprendizaje en el terreno de la investigación criminal también se manifiesta en cierto "olfato policial" que desarrollan los agentes policiales a partir de la práctica y la experiencia: no solamente para las tareas de calle, sino en términos generales para comprender el lenguaje y los modos de comunicación de los investigados: "no hay como el olfato del investigador para entender lo que dicen los delincuentes en sus comunicaciones" (Entrevistado $N^{\circ} 23$ - PSA, 25/11/2016). Para un análisis minucioso de las acepciones y utilizaciones del término olfato policial, confróntese GARRIGA (2013), pp. 489-509.

${ }^{56}$ Entrevistado $N^{\circ} 32$ - PSA, 07/11/2018.

${ }^{57}$ Entrevistado $N^{\circ} 28-$ PSA, 18/08/2016.

${ }^{58}$ Entrevistado $N^{\circ} 35$ - PSA, 09/01/2019.
} 
juicios orales, y viste, no cualquiera esta para eso. (...) Hacer un hecho como el que hicimos el otro día, salir en los diarios, en todos lados..." 59

Finalmente, las entrevistas sugieren que el saber-hacer del investigador criminal a nivel federal, combinación de arte y técnica, tiene como último correlato la ausencia de un criterio consensuado, preciso, para evaluar el éxito de las investigaciones. Parte de esta dificultad radica en la difícil visibilidad que tiene la cantidad y la cualidad de la labor de investigación policial vis a vis la que realiza, por ejemplo, la vigilancia y los controles preventivos en la PSA:

"El trabajo nuestro no se ve porque, por ejemplo, para la [seguridad] preventiva hoy tenés 5 vuelos, hiciste los 5 , atendiste a 400 personas, hiciste los cacheos, el control de carga, de equipajes, no encontraste ninguna novedad... pero son 5 vuelos. Nosotros, para llegar a un allanamiento, estuvimos trabajando dos años, nada te da la garantía de que vuelvas con la información de la calle que fuiste a buscar". ${ }^{60}$

Los investigadores policiales y los funcionarios judiciales utilizan diferentes medidas a la hora de evaluar el resultado de las investigaciones, entre las cuales se destacan, y a veces se contraponen, las siguientes: la cantidad y el valor de las sustancias incautadas (ej. para drogas o contrabando); la cantidad de delincuentes atrapados y/o la posición que ocupan dentro de las organizaciones criminales; la ausencia de errores en los procedimientos que permite llegar a juicios y condenas; el reconocimiento por parte de las autoridades judiciales de la labor de la fuerza. De todas formas, siendo tantos los elementos intervinientes en las investigaciones y su eficacia, los indicadores mencionados son muy discutidos, explicando la ausencia de criterios claros y consensuados sobre la eficacia investigativa.

\section{Conclusiones}

El presente trabajo procuró contribuir al conocimiento del vínculo entre la discrecionalidad policial y la investigación criminal a nivel federal en Argentina, a partir del estudio de una fuerza policial específica: la PSA. Un primer hallazgo que construimos a partir de la recopilación y el análisis de la información remite al "espacio" de la discrecionalidad policial en la investigación criminal. El análisis de las normativas, las variaciones en las causas con participación de la PSA y los testimonios de los entrevistados indican el peso de las decisiones judiciales en las investigaciones policiales a nivel federal. Notamos que, en el caso analizado, a la hora de determinar cuánto, qué y cómo se investiga, la policía es influida por los lineamientos que emanan de la interacción con los operadores judiciales. Adicionalmente, las decisiones judiciales se ven afectadas por la influencia de sectores de la prensa y el gobierno. De todas formas, generamos y analizamos información limitada para profundizar en este asunto, y futuros trabajos deberán diseñar otras propuestas de investigación para asir y mensurar esta cuestión tan compleja, que afecta la dirección de la persecución penal en las causas federales en la Argentina.

\footnotetext{
${ }^{59}$ Entrevistado $\mathrm{N}^{\circ} 32$ - PSA, 11/12/2018.

${ }^{60}$ Entrevistado $\mathrm{N}^{\circ} 28$ - PSA, 18/08/2016.
} 
En segundo lugar, los testimonios relevados muestran que el "contenido" de la discrecionalidad policial suele ser valorada por los operadores judiciales como un saberhacer profesional. Si bien reconocen que deben estar atentos a que no degenere hacia investigaciones contaminadas, los actores judiciales y del ministerio público perciben que la discrecionalidad es una condición necesaria para el desarrollo de las investigaciones, pues los agentes policiales están en el terreno, cumpliendo una función y realizando un despliegue que los funcionarios de justicia no hacen ni pueden hacer.

Indagando en este saber-hacer profesional encontramos elementos vinculados al modelo técnico-profesional (la relevancia del conocimiento de los códigos y procedimientos, el lenguaje y el protocolo judicial) y al modelo artesanal (la importancia de la experiencia, del trabajo en terreno, de la cualidad personal). Es de notar que esta combinación de elementos técnicos y artesanales en el saber profesional de los investigadores apunta, a diferencia de los agrupamientos preventivos, a poder mimetizarse con diferentes ambientes, a fin de recabar información para identificar posibles delitos y delincuentes; así como también a tener la "adaptabilidad" para manejarse con actores de peso como la justicia, la prensa o el mismo gobierno.

Llegados a este punto, esperamos que el caso estudiado permita precisar caracterizaciones sobre la discrecionalidad policial y la investigación criminal que trasciendan a la fuerza analizada y que aporten al debate general sobre cómo diseñar e implementar mejores sistemas de investigación del delito a nivel federal en Argentina. Futuros estudios deberán corroborar nuestras inferencias en las otras fuerzas federales, y ahondar en criterios para completar la evaluación normativa de nuestro asunto. 
GUTIÉRREZ, Mariana; COSTANTINO, Gabriel, “Entre el arte y la técnica: la discrecionalidad policial en la investigación criminal. El caso de la Policía de Seguridad Aeroportuaria en Argentina".

\section{Referencias}

ANDERSEN, Martín (2002): La policía. Pasado, presente y propuestas para el futuro (Buenos Aires: Sudamericana).

ARSLANIÁN, León (2011): Seguridad ciudadana: hacia un cambio de paradigma. Tercer Seminario Internacional sobre Políticas de Seguridad (Córdoba: Universidad Nacional de Villa María).

BERGMAN, Marcelo; LANGER, Máximo (2015): "El nuevo código procesal penal nacional acusatorio: aportes empíricos para la discusión en base a la experiencia en la Provincia de Buenos Aires", en: Revista de derecho procesal penal (n 1), pp. 51-80.

BIANCIOTTO, Lucía (2013): "Previsión, anticipación y viveza. A propósito de la relación entre prácticas policiales y ámbito judicial en Rosario”, en: FREDERIC, Sabina; GALVANI, Mariana; GARRIGA ZUCAL, José; RENOLDI, Brígida (edits.), De armas llevar. Estudios socioantropológicos sobre los quehaceres de policías y de las fuerzas de seguridad (La Plata: Ediciones de periodismo y comunicación), pp. 305326.

BINDER, Alberto (2002): "La reforma de la justicia penal: entre el corto y el largo plazo", en: Sistemas Judiciales ( $\left.{ }^{\circ} 3\right)$, pp. 67-72.

BRODEUR, Jean-Paul (2011): Las caras de la policía. Prácticas y percepciones, (Buenos Aires: Prometeo).

BRONITT, Simon; STENNING, Philip (2011): "Understanding Discretion in Modern Policing”, en: Criminal Law Journal (vol. 35, n 6), pp. 319-332.

CAMOU, Antonio; MORENO, José (2005): "Crisis, reforma y contrarreforma del Sistema de Seguridad de la Provincia de Buenos Aires: la cultura institucional, los actores políticos y la misión de los reformadores”, en: KAMINSKY, Gregorio, Tiempos inclementes. Culturas policiales y seguridad ciudadana, (Remedios de Escalada: Ediciones de la UNLA), pp. 141-172.

CENTRO DE ESTUDIOS DE JUSTICIA DE LAS AMÉRICAS (CEJA) (2007): Desafíos del Ministerio Público Fiscal en América Latina, (Santiago de Chile: CEJA).

CENTRO DE ESTUDIOS DE JUSTICIA DE LAS AMÉRICAS (CEJA) (2007): Persecución de delitos complejos: experiencias en la investigación criminal, (Santiago de Chile: CEJA).

CENTRO DE ESTUDIOS DE JUSTICIA DE LAS AMÉRICAS (CEJA) (2005): Reformas procesales penales en América Latina: Resultados del proyecto de seguimiento, (Santiago de Chile: CEJA)

CENTRO DE ESTUDIOS LEGALES Y SOCIALES (CELS) (1998): Informe Anual 1997, (Buenos Aires: CELS).

CENTRO DE ESTUDIOS LEGALES Y SOCIALES (CELS) (2004): Políticas de Seguridad Ciudadana y Justicia Penal (Buenos Aires: Siglo XXI).

COSTANTINO, Gabriel (2016): "Presidentes, gobernadores y políticas de seguridad ciudadana en Argentina: ¿un juego racional?”, en: III Jornadas de Investigación en Política y Gobierno (San Martín, Argentina).

COSTANTINO, Gabriel; GUTIERREZ, Mariana (2017): "La reforma policial permanente", Bastión Digital, 01/02/2017, en: http://ar.bastiondigital.com/notas/lareforma-policial-permanente [visitado el 06.05.2020]. 
COSTANTINO, Gabriel; GUTIÉRREZ, Mariana (2017): "Reforma policial y profesionalización en seguridad aeroportuaria (2005-2015)", en: Documentos y Aportes en Administración Pública y Gestión Estatal (n 28), pp. 59-90.

DEWEY, Matías (2015): El orden clandestino. Política, fuerzas de seguridad y mercados ilegales en la Argentina (Buenos Aires: Katz Editores).

DIAZ, Sofia, "El Sistema Acusatorio en los procesos penales de América del Sur", en: Revista Argumentos, (n 4$)$, pp. 1-19.

DUCE, Mauricio (2005): "El ministerio público fiscal en la reforma procesal penal en América latina: visión general acerca del estado de los cambios", en: Sistemas Judiciales ( $\left.\mathrm{n}^{\circ} 8\right)$, pp. 65-82.

EPSTEIN, Lee; KING, Gary (2002): "The rules of inference", en: The University of Chicago Law Review (vol. 69, $\mathrm{n}^{\circ}$ 1), pp. 1-133.

ERICSON, Richard (1989): "Patrolling the Facts: Secrecy and Publicity in Police Work", en: The British Journal of Sociology (vol. 40, n 2), pp. 205-226.

ESCUDERO, Andrés (2017): "La reforma policial como problema de investigación. Una revisión bibliográfica crítica y multidisciplinaria para el estudio del fenómeno en la provincia de Buenos Aires", en: Revista de investigación interdisciplinaria en métodos experimentales $\left(\mathrm{n}^{\circ} 1\right)$, pp. 83-113.

FREDERIC, Sabina (2008): Los usos de la fuerza pública. Debates sobre militares y policías en las ciencias sociales de la democracia (Buenos Aires: Universidad Nacional de General Sarmiento).

FREDERIC, Sabina; GALVANI, Mariana; GARRIGA ZUCAL, José; RENOLDI, Brígida (edits.) (2013): De armas llevar. Estudios socioantropológicos sobre los quehaceres de policías y de las fuerzas de seguridad (La Plata: Ediciones de periodismo y comunicación).

GARRIGA ZUCAL, José (2013): "Usos y representaciones del 'olfato policial' entre los miembros de la policía bonaerense", en: DILEMAS: Revista de Estudos de Conflito e Controle Social (vol. 6, n 3 ), pp. 489-509.

GEORGE, Alexander; BENNETT, Andrew (2005): Case Studies and Theory Development in the Social Sciences (Cambridge: MIT Press).

GONZÁLEZ, Gustavo (ed.) (2017): El subsistema fronterizo argentino: mercados ilegales, delito económico organizado y regulaciones estatales (Buenos Aires: Café de las Ciudades).

GONZÁLEZ, Gustavo (2011): "Mapeando el trabajo policial. La in/experiencia en el "oficio" como variable de diferenciación", en: Delito y Sociedad. Revista de Ciencias Sociales (n $\left.{ }^{\circ} 32\right)$, pp. 53-86.

HELMKE, Gretchen (2002) "The Logic of Strategic Defection: Court-Executive Relations in Argentina under Dictatorship and Democracy", en: American Political Science Review (vol. 96, n 2), pp. 291-303.

INGRAM, Matthew (2015): "Judicial Power in Latin America", en: Latin American Research Review (vol. 50, n 1), pp. 250-260.

LORENZ, Mariana (2018): "Definiendo la profesión policial", en: Trabajo y Sociedad ( ${ }^{\circ}$ 30), pp. 347-369.

MARENIN, Otwin (2007): "Autonomy and the Police", en: GREENE, Jack R. (ed.), Encyclopedia of Police Science (Nueva York: Routledge), pp. 86-88.

MÉNDEZ, Juan; O’DONNELL, Guillermo; PINHEIRO, Paulo (2002): La (in)efectividad de la ley y la exclusión en América Latina (Buenos Aires: Paidós). 
MONJARDET, Dominique (2010): Lo que hace la policía. Sociología de la fuerza pública, (Buenos Aires: Prometeo).

OFICINA DE LAS NACIONES UNIDAS CONTRA LA DROGA Y EL DELITO (UNODC) (2004): "Convención de las Naciones Unidas contra la delincuencia organizada transnacional y sus protocolos" (Nueva York: Naciones Unidas).

OFICINA DE LAS NACIONES UNIDAS CONTRA LA DROGA Y EL DELITO (UNODC) (2010): "Policía. Investigación de delitos. Manual de instrucciones para la evaluación de la justicia penal" (Viena: Naciones Unidas).

REINER, Robert (2000): The Politics of the Police (Nueva York: Oxford University Press).

RENOLDI, Brígida (2010): "Persona, agencia y Estado: rutinas de instrucción judicial en el proceso federal argentino", en: Cuadernos de Antropología Social ( $\left.{ }^{\circ} 32\right)$, pp. 95120.

RODRIGUEZ ALZUETA, Esteban (2018): "La desmonopolización de la violencia: la subordinación negociada y encantada en las policías argentinas", en: Revista Electrónica de Estudios Penales y de la Seguridad ( $\left.\mathrm{n}^{\circ} 2\right)$, pp. 1-27, en: https://www.ejc-reeps.com/5_articulo_Esteban_Rodriguez.pdf $\quad$ [visitado el 06.05.2020].

SAIN, Marcelo (2007): El Leviatán Azul. Policía y Política en la Argentina (Buenos Aires: Siglo XXI).

SAIN, Marcelo (2015): La regulación del narcotráfico en la provincia de Buenos Aires (Buenos Aires: Editorial UMET).

SAIN, Marcelo (2002): Seguridad, democracia y reforma del sistema policial en la Argentina (Buenos Aires: Fondo de Cultura Económica). 